CZASOPISMO INŻYNIERII LĄDOWEJ, ŚRODOWISKA I ARCHITEKTURY JOURNAL OF CIVIL ENGINEERING, ENVIRONMENT AND ARCHITECTURE

JCEEA, t. XXXIII, z. 63 (3/16),lipiec-wrzesień 2016, s. 211-218

\author{
Karolina KURTZ-ORECKA ${ }^{1}$
}

\title{
WSPÓŁCZYNNIK REDUKCJI TEMPERATURY W OBLICZENIACH STRAT CIEPŁA DO PRZESTRZENI NIEOGRZEWANYCH PIWNIC
}

\begin{abstract}
Sukcesywne podnoszenie wymagań oszczędności energii, a także zróżnicowanie warunków otoczenia budynku charakterystyczne dla lokalizacji, wymagają szczegółowego podejścia do obliczeń potrzeb cieplnych budynków nowoprojektowanych, jak i istniejących. Zastosowanie w obliczeniach bilansu zapotrzebowania na energię na potrzeby ogrzewania i wentylacji, stałej zryczałtowanej wartości współczynnika redukcji temperatury wydaje się być podejściem niewłaściwym, z uwagi na brak szczegółowych danych krajowych.

W artykule, na przykładzie wyników uzyskanych dla trzech obiektów, przedstawiono zmienność współczynnika redukcji temperatury stropów nad nieogrzewanymi piwnicami, w zależności od izolacyjności termicznej przegród zamykających przestrzeni ogrzewaną i nieogrzewaną oraz warunków środowiska zewnętrznego. Wykazano, że zastosowanie do obliczeń potrzeb cieplnych budynku stałej wartości współczynnika redukcji temperatury wiąże się z przeszacowaniem start ciepła $\mathrm{z}$ powierzchni stropu nad nieogrzewanymi piwnicami, co prowadzi do istotnego niedostosowania modelu obliczeniowego budynku w odniesieniu do jego rzeczywistego stanu. Przy projektowaniu budynków przeszacowanie zużycia energii często wiąże się z koniecznością wprowadzania kosztownych rozwiązań pozwalających na dotrzymanie wartości granicznych wskaźnika zapotrzebowania na nieodnawialną energię pierwotną, stąd poprawność przyjętego modelu obliczeniowego nabiera istotnej wagi. W przypadku budynków istniejących poddawanych procesowi termomodernizacji, szczegółowo wyznaczony współczynnik redukcji temperatury, a za tym straty ciepła, pozwalają na wskazanie oszczędności energii związanej z ociepleniem ścian nieogrzewanych piwnic. Dokładny opis modelu budynku jest również istotny przy rozliczaniu wsparcia finansowego udzielonego na poprawę efektywności energetycznej budynku i raportowaniu z osiągniętego efektu ekologicznego, ponieważ pozwala na dokładniejsze szacowanie redukcji emisji $\mathrm{CO}_{2}$.
\end{abstract}

Słowa kluczowe: wymiana ciepła pomiędzy przestrzenią ogrzewaną i nieogrzewaną, ocieplenie stropów piwnic, termomodernizacja, raportowanie z osiągniętego efektu ekologicznego

\footnotetext{
${ }^{1}$ Karolina Kurtz-Orecka, Zachodniopomorski Uniwersytet Technologiczny w Szczecinie, Katedra Fizyki Budowli i Materiałów Budowlanych, al. Piastów 50, 70-311 Szczecin; tel. 608691975; kurtz@zut.edu.pl,karolinakurtz@gmail.com
} 


\section{Wprowadzenie}

W obliczeniach charakterystyki energetycznej budynku - zapotrzebowania na energię na potrzeby ogrzewania i wentylacji [1], jedną ze składowych bilansu są straty ciepła przez przenikanie opisane zależnością (1). Obejmują one przenoszenie ciepła przez przegrody $\mathrm{w}$ bezpośrednim kontakcie $\mathrm{z}$ powietrzem zewnętrznym $(e)$, do przestrzeni przyległej $(j)$, w kontakcie z gruntem $(g)$ oraz pomiędzy środowiskiem o regulowanej i nieregulowanej temperaturze $(u)$. Z czterech składowych przenoszenia ciepła opisanych zależnością (2) tylko pierwsza związana jest wprost $\mathrm{z}$ różnicą temperatury wewnętrznej (w ujęciu normy PN-EN ISO 13790 [2] oraz metodyki [1]) oraz średniej miesięcznej temperatury zewnętrznej, ponieważ obejmuje przenikanie ciepła przez przegrody stanowiące bezpośrednią granicę termiczną pomiędzy warunkami wewnętrznymi i zewnętrznymi. Pozostałe składowe, $H_{t r, i u e}, H_{t r, i j}$, $H_{t r, i g}$, dla których różnica temperatury pomiędzy środowiskami jest zazwyczaj mniejsza [3], podlegają zmniejszeniu poprzez uwzględnienie współczynnika redukcji temperatury.

$$
\begin{aligned}
& Q_{t r, n}=H_{t r}\left(\theta_{\mathrm{int}, H}-\theta_{e, n}\right) t_{M}, \\
& H_{t r}=H_{t r, i e}+H_{t r, i u e}+H_{t r, i j}+H_{t r, i g},
\end{aligned}
$$

gdzie: $H_{t r}$ - współczynnik przenoszenia ciepła przez przenikanie, [W/K] [7],

$Q_{t r n}$ - ilość ciepła przenoszonego ze strefy ogrzewanej przez przenikanie w $n$-tym okresie obliczeniowym, $[\mathrm{kWh} / \mathrm{m}$-c $]$,

$t_{M}$ - czas, [h],

$\theta$ - temperatura, $\left[{ }^{\circ} \mathrm{C}\right]$,

indeksy opisano w tekście.

W przypadku obliczeń start ciepła do przestrzeni nieogrzewanej $(u)$, współczynnik redukcji temperatury uwzględnia różnicę pomiędzy temperaturą przestrzeni nieogrzewanej oraz temperaturą zewnętrzną [4]. Może być wyznaczony jedną z trzech metod:

- z zależności (3) w przypadku, gdy znana jest temperatura przestrzeni nieogrzewanej $\theta_{u}$,

- przy wykorzystaniu współczynników start ciepła przez przenikanie i wentylację z przestrzeni ogrzewaj do nieogrzewanej $H_{\text {iu }}$ oraz z przestrzeni nieogrzewanej do otoczenia $H_{u e}$ zgodnie ze wzorem (4),

- poprzez przyjęcie zryczałtowanej wielkości określonej w normie PN-EN $12831[4]$.

$$
b_{u}=\frac{\theta_{\mathrm{int}, i}-\theta_{u}}{\theta_{\mathrm{int}, i}-\theta_{e}}
$$




$$
b_{u}=\frac{H_{u e}}{H_{i u}+H_{u e}},
$$

gdzie oznaczenia jak w zależnościach (1) i (2) oraz w tekście. We wzorze (3) temperatura przestrzeni nieogrzewanej określona jest zależnością [7]:

$$
\theta_{u}=\frac{\phi+\theta_{i} H_{i u}+\theta_{e} H_{u e}}{H_{i u}+H_{u e}},
$$

gdzie: $\Phi$ - strumień cieplny [W], wytwarzany w przestrzeni nieogrzewanej, pozostałe symbole zgodnie z objaśnieniami do zależności (1) i (2).

W przypadku przenoszenia ciepła z ogrzewanej części budynku do przestrzeni nieogrzewanych piwnic, zryczałtowana wartość współczynnika redukcji temperatury zgodnie z normą PN-EN 12831 [4] przyjmuje wartość stałą, wynoszącą 0,8 . Z uwagi na brak danych krajowych [5], w normie [4] przyjęto wielkości orientacyjne zaproponowane w normie europejskiej EN 12831. Należy zwrócić uwagę, że stała, dla danej przestrzeni wartość współczynnika redukcji temperatury nie pozwala na uwzględnienie wpływu na wielkość strat ciepła izolacyjności termicznej obudowy przestrzeni nieogrzewanej. W praktyce inżynierskiej utrudnia to m.in. uargumentowanie objęcia działaniami termomodernizacyjnymi powierzchni ograniczających przestrzenie nieogrzewane, z uwagi na brak możliwości wskazania oszczędności energii. W związku z tym w audycie energetycznym często podjęta zostaje decyzja o ociepleniu ścian zewnętrznych jedynie do płaszczyzny stropu nad piwnicą, co może skutkować wystąpieniem krytycznej temperatury na powierzchni wewnętrznej węzła połączenia ściany zewnętrznej ze stropem. Stąd zastosowanie w obliczeniach zapotrzebowania na energię w budynku stałej wartości współczynnika redukcji temperatury wydaje się być podejściem niewłaściwym, szczególnie we wskazanej sytuacji braku danych krajowych [5]. Systematycznie zaostrzane wymagania oszczędności energii [6], pociągają za sobą konieczność szczegółowego podejścia do obliczeń potrzeb cieplnych budynków nowoprojektowanych, jak i istniejących.

Zmienność współczynnika redukcji temperatury, w zależności od izolacyjności termicznej przegród zamykających przestrzeń ogrzewaną i nieogrzewaną oraz warunków panujących w otoczeniu budynku, zostanie przedstawiona na przykładzie trzech istniejących obiektów mieszkalnych wielorodzinnych.

\section{Charakterystyka budynków}

Przyjęte do analizy budynki zlokalizowane są na terenie Szczecina. Wszystkie obiekty wzniesiono w technologii prefabrykowanej, w systemie Szczecińskim, w okresie od 1971 do 1989 roku. Budynki zróżnicowane są w zakresie geometrii rzutu przyziemia, skali, kubatury oraz liczby lokali miesz- 
kalnych. Podstawową ich charakterystykę zestawiono w tabeli 1 i 2 . Budynki 1 i 2 na początku lat 90 . XX w. zostały ocieplone w płaszczyźnie ścian zewnętrznych styropianem fasadowym o grubości $5 \mathrm{~cm}$. W przypadku budynku $\mathrm{nr} 1 \mathrm{izo}-$ lacja termiczna została wykonana do poziomu dolnej płaszczyzny stropu piwnic, zaś w przypadku budynku nr 2 - izolację sprowadzono na $40 \mathrm{~cm}$ poniżej płaszczyzny dolnej stropu. Budynek nr 3 nie jest dodatkowo izolowany termicznie poza warstwą wełny mineralnej prefabrykowanej płyty warstwowej kondygnacji nadziemnych.

Tabela 1. Charakterystyka analizowanych budynków

Table 1. Characteristics of analyzed buildings

\begin{tabular}{|c|c|c|c|c|}
\hline Opis & Jedn. & Budynek 1 & Budynek 2 & Budynek 3 \\
\hline Rok budowy & - & 1971 & 1975 & 1989 \\
\hline $\begin{array}{c}\text { Liczba lokali mieszkalnych } \\
\text { Temperatura w pomieszczeniach } \\
\text { ogrzewanych }\end{array}$ & szt. & 20 & 75 & 205 \\
\hline $\begin{array}{c}{ }^{\circ} \mathrm{C} \\
\text { Powierzchnia użytkowa }\end{array}$ & $16,20,24$ & $16,20,24$ & $16,20,24$ \\
\hline o regulowanej temperaturze, $A_{f}$ & $\mathrm{~m}^{2}$ & 981 & 3393 & 10093 \\
\hline Kiczba kondura ogrzewana & $\mathrm{m}^{3}$ & 2451 & 8789 & 19257 \\
\hline Kształt rzuty przyziemia & - & 5 & 5 & $10 \mathrm{i} 11$ \\
\hline Wymiary rzutu budynku & $\mathrm{m}$ & $16,82 \times 14,34$ & $86,95 \times 9,97$ & $\begin{array}{c}31,6 \times 14,26 / \\
\text { Kwadrat }\end{array}$ \\
\hline $\begin{array}{c}\text { Powierzchnia stropu piwnic do obli- } \\
\text { czeń strat ciepła, } A_{\text {str }} \text { PIW }\end{array}$ & $\mathrm{m}^{2}$ & 241 & 795 & 1073 \\
\hline $\begin{array}{c}\text { Powierzchnia obudowy przestrzeni } \\
\text { nieogrzewanej piwnic w kontakcie } \\
\text { z otoczeniem, } A_{\text {ue }}\end{array}$ & $\mathrm{m}^{2}$ & 112 & 266 & 157 \\
\hline
\end{tabular}

Tabela 2. Charakterystyka izolacyjności termicznej oraz wentylacyjna przestrzeni nieogrzewanej analizowanych budynków

Table 2. Thermal insulation and ventilation characteristics of unconditioned space of analyzed buildings

\begin{tabular}{|c|c|c|c|}
\hline Opis & Budynek 1 & Budynek 2 & Budynek 3 \\
\hline Współczynnik przenikania ciepła, [W/(m² $\mathrm{K})]$ & 1,05 \\
\hline Strop nad piwnicami & $1,12-1,39$ & 1,05 & 4,17 \\
\hline $\begin{array}{c}\text { Ściany piwnic w kontakcie z powietrzem } \\
\text { zewnętrznym, nieizolowane termicznie }\end{array}$ & 1,43 & 4,26 & - \\
\hline $\begin{array}{c}\text { Sciany piwnic w kontakcie z powietrzem } \\
\text { zewnętrznym, izolowane termicznie }\end{array}$ & - & 0,55 & 2,3 \\
\hline Oknna w ścianach piwnic & 2,3 & 2,3 & 5,0 \\
\hline Bramy garażowe & 2,6 & - & \\
\hline Współczynnik start ciepła przez wentylację, [W/K] \\
\hline \multicolumn{2}{|l|}{\begin{tabular}{c} 
Przestrzeń nieogrzewanych piwnic \\
\hline
\end{tabular}}
\end{tabular}




\section{Współczynnik redukcji temperatury dla analizowanych stropów nieogrzewanych piwnic}

Zmienność współczynnika redukcji temperatury, temperatury przestrzeni nieogrzewanej oraz strat ciepła $\mathrm{z}$ powierzchni stropu nad piwnicą w zależności od izolacyjności termicznej stropu piwnic oraz ścian zewnętrznych piwnic przeanalizowano $\mathrm{w}$ wariantach:

- warianty 0 i 4 (W0, W4) - współczynnik redukcji temperatury oraz temperaturę w przestrzeni piwnic przyjęto jako wartości stałe odczytane z norm [4],[8] stan przed (W0) i po termomodernizacji obejmującej powierzchnię stropu piwnic oraz ściany zewnętrzne piwnic (W4),

- warianty pośrednie 1, 2 i 3 (W1, W2, W3), w których współczynnik redukcji temperatury oraz temperaturę $w$ przestrzeni nieogrzewanych piwnic wyznaczono w funkcji izolacyjności termicznej przegród z zależności (3) i (5); wariant 1 - przed termomodernizacją, $2-\mathrm{z}$ ociepleniem tylko stropu piwnic, 3 - z ociepleniem stropu oraz ścian zewnętrznych piwnic.

W przypadku przyjęcia stałej wartości współczynnika redukcji temperatury $b_{u}$, temperaturę nieogrzewanych piwnic można ustalić na podstawie normy PN-82/B-02403 [8]. W odniesieniu do analizowanych budynków wynosi ona $4^{\circ} \mathrm{C}$. Uzyskaną z zależności (3) i (5) zmienność temperatury przestrzeni nieogrzewanych piwnic oraz współczynnika redukcji temperatury w układzie miesięcznym typowego roku meteorologicznego stacji Szczecin-Dąbie, zestawiono na rysunkach 1 i 2.

Straty ciepła z powierzchni stropu piwnic odniesione do $1 \mathrm{~m}^{2}$ jego powierzchni przedstawiono na rysunku 3 . W prezentacji wyników przyjęto ozna-

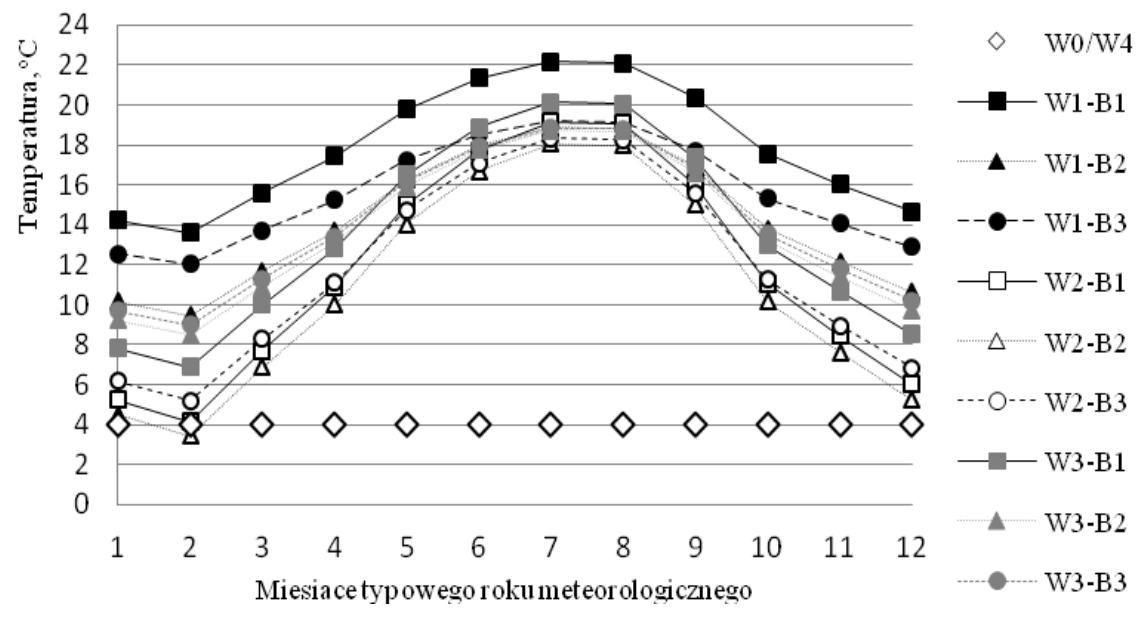

Rys. 1. Przebieg roczny temperatury przestrzeni nieogrzewanych piwnic

Fig. 1. The annual temperature variation of unconditioned basement space 
czenia: B1 - budynek nr 1, B2 - budynek nr 2, B3 - budynek nr 3 . W wariantach W0 i W4 temperatura piwnic oraz współczynnik redukcji temperatury są wartościami stałymi.

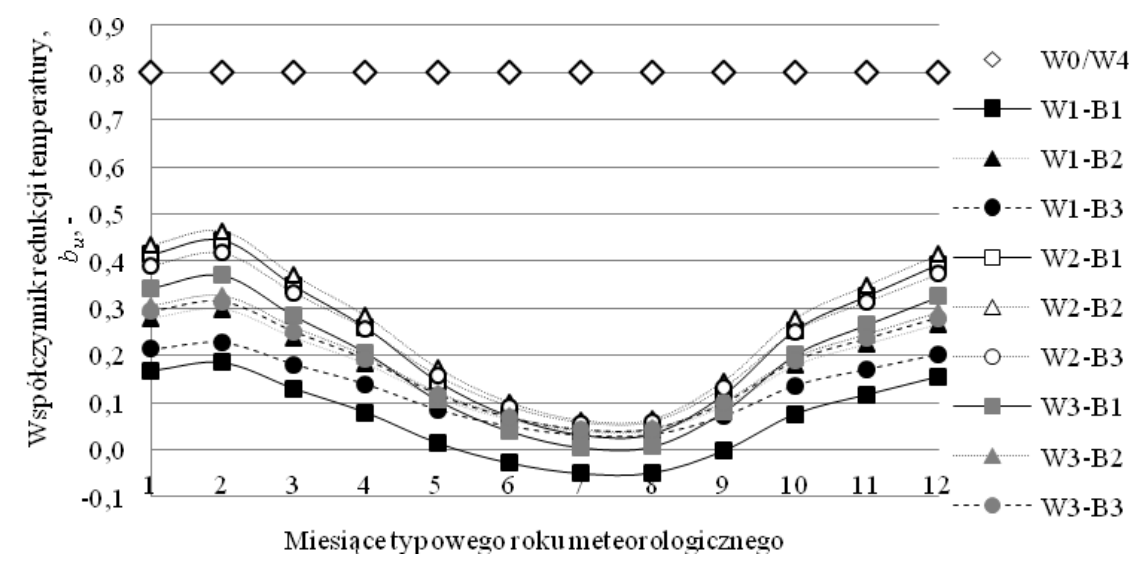

Rys. 2. Zmienność współczynnika redukcji temperatury dla analizowanych przypadków

Fig. 2. The variation of temperature adjustment factor of analyzed cases

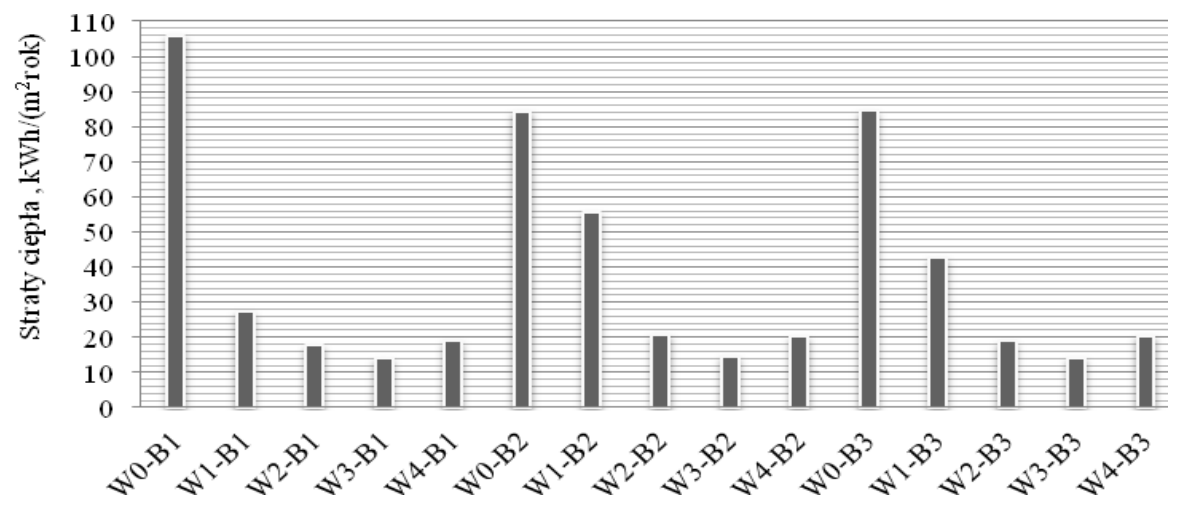

Rys. 3. Starty ciepła z powierzchni stropu nad nieogrzewanymi piwnicami

Fig. 3. Heat losses through the surface of the ceiling above unconditioned basements

Na podstawie uzyskanych wyników można stwierdzić, że zarówno temperatura w przestrzeni nieogrzewanych piwnic, jak i współczynnik redukcji temperatury podlegają zmienności $\mathrm{w}$ typowym roku meteorologicznym $\mathrm{w}$ zależności od izolacyjności termicznej ich obudowy oraz warunków panujących w przestrzeni ogrzewanej i otoczeniu. Temperatura przestrzeni nieogrzewanej i współ- 
czynnik redukcji temperatury są istotnie różne od przybliżonych wartości normowych. Ponadto wprowadzenie izolacji termicznej ścian zewnętrznych piwnic przyczynia się do wzrostu szacowanej temperatury w przestrzeni nieogrzewanej, powodując tym samym zmniejszenie start ciepła przez przenikanie przez powierzchnię stropu nad piwnicami.

\section{Wnioski}

Wykorzystanie w obliczeniach zapotrzebowania budynku na energię na potrzeby ogrzewania stałej wartości współczynnika redukcji temperatury $b_{u}$, wiąże się ze znaczącym przeszacowaniem start ciepła z powierzchni stropu nad nieogrzewanymi piwnicami, co prowadzi do istotnego niedostosowania modelu obliczeniowego budynku w odniesieniu do jego rzeczywistego stanu.

Przy projektowaniu budynków przeszacowanie zużycia energii wiąże się z często koniecznością wprowadzania kosztownych rozwiązań pozwalających na dotrzymanie wartości granicznych wskaźnika zapotrzebowania na nieodnawialną energię pierwotną $E P$, stąd jakość modelu obliczeniowego przekłada się na wymiar ekonomiczny inwestycji.

W przypadku budynków istniejących poddawanych procesowi termomodernizacji, szczegółowo wyznaczony współczynnik redukcji temperatury, a w konsekwencji oszacowane straty ciepła, pozwalają na wykazanie oszczędności energii związanej z ociepleniem ścian nieogrzewanych piwnic. Uszczegółowienie obliczeń umożliwia również dokładniejsze, niż w przypadku zastosowania stałych współczynników redukcji temperatury, szacowanie zapotrzebowania na energię $\mathrm{w}$ budynku $\mathrm{w}$ stanie przed i po planowanej termomodernizacji, warunkując często dotrzymanie wymagan programów wsparcia finansowego poprawy efektywności energetycznej. Dokładny opis modelu budynku jest również istotny przy rozliczaniu wsparcia finansowego udzielonego na poprawę efektywności energetycznej budynku i raportowaniu z osiągniętego efektu ekologicznego, ponieważ pozwala na dokładniejsze szacowanie redukcji emisji $\mathrm{CO}_{2}$.

\section{Literatura}

[1] Rozporządzenie Ministra Infrastruktury i Rozwoju z dn. 27.02.2015 r. w sprawie metodologii wyznaczania charakterystyki energetycznej budynku lub części budynku oraz świadectw charakterystyki energetycznej, Dz.U. (2015) poz. 376.

[2] Polska Norma PN-EN ISO 13790:2009 Energetyczne właściwości użytkowe budynków - Obliczenia zużycia energii do ogrzewania i chłodzenia. PKN, Warszawa 2009.

[3] Strzeszewski M. Współczynnik redukcji temperatury w metodyce obliczania obciążenia cieplnego wg PN-EN 12831. http://www.is.pw.edu.pl/ michal_strzeszewski/ ioiw/12831WRT.pdf (dostęp 20.05.2016).

[4] Polska Norma PN-EN 12831:2006 Instalacje ogrzewcze budynkach - Metoda obliczania projektowanego obciążenia cieplnego. PKN, Warszawa 2006. 
[5] Kasperkiewicz K. Nowe zasady obliczania projektowanego obciążenia cieplnego pomieszczeń i budynków wg PN-EN 12831:2006 „Instalacje ogrzewcze w budynkach - Metoda obliczania projektowego obciążenia cieplnego". http://www.itb.pl/ nf/PDF/KK05.pdf (dostęp 20.05.2016).

[6] Rozporządzenie Ministra Infrastruktury z dn. 12.04.2002 r. w sprawie warunków technicznych, jakim powinny odpowiadać budynki i ich usytuowanie, Dz.U. 75, poz 690 z późn. zm.

[7] Polska Norma PN-EN ISO 13789: 2008 Cieplne właściwości użytkowe budynków Współczynniki przenoszenia ciepła przez przenikanie i wentylację - Metoda obliczania. PKN, Warszawa 2008.

[8] Polska Norma PN-82/B-02403 Ogrzewnictwo - Temperatury obliczeniowe zewnętrzne. PKNMiJ, Warszawa 1982.

\section{TEMPERATURE ADJUSTMENT FACTOR USED IN CALCULATIONS OF ENERGY LOSSES TO UNCONDITIONED CELLAR SPACE}

\section{S u m m a r y}

Gradual increase of energy saving requirements, as well as the diversity of environmental conditions specific to the location of a building, require specific approach towards the calculation of thermal needs of newly designed and existing buildings. The use of the heating energy demand balance of and fixed rate of temperature adjustment factor in the calculations seems to be a wrong approach, because of the lack of detailed national data.

In the article, on the example of the results obtained from three objects, the adjustment factor of the ceilings above the unconditioned basements, depending on the thermal insulation of envelope partitions as well as the conditions of the external environment have been presented. It has been shown that the use of the constant value of the adjustment factor for the calculation of the heat demand of the building is associated with the overestimation of heat losses from the surface of the ceiling above the basement floor, which leads to a significant inadequacy of calculation model of the building in relation to its actual condition. When designing buildings the overestimation of energy often requires introduction of expensive solutions to meet the limit values of the indicator of demand for non-renewable primary energy, hence the correctness of the adopted calculation model is gaining substantial importance. In case of existing buildings undergoing a general thermal retrofit, a temperature adjustment factor designed in a detailed manner, and so the heat losses, allows to identify energy savings associated with the insulation of walls of unconditioned basements. The exact description of the building model is also important when accounting financial support for improvement of the energy efficiency of the building as well as reporting the achieved environmental effect, because it allows for more accurate estimation of $\mathrm{CO}_{2}$ emission reduction.

Keywords: heat flow between conditioned and unconditioned space, thermal retrofit of basement ceilings, thermal retrofit, reporting of achieved environmental effect

DOI:10.7862/rb.2016.203

Przestano do redakcji: $13.06 .2016 r$.

Przyjęto do druku: 30.11 .2016 r. 